\title{
Ewing's sarcoma/primitive neuroectodermal tumour of the prostate: A case report and literature review
}

\author{
Tao Wu, MD; Tao Jin, MD; Deyi Luo, MD; Lin Chen, MD; Xiang Li, MD \\ Department of Urology, West China Hospital, Sichuan University, Chengdu, China
}

Cite as: Can Urol Assoc J 2013;7(5-6):e458-9. http://dx.doi.org/10.5489/cuaj.1393 Published online June 12, 2013.

\section{Abstract}

We present a case of Ewing's sarcoma and primitive neuroectodermal tumour (PNET) of the prostate. A 29-year-old male presented with difficult defecation and anus distention; on magnetic resonance imaging scan of the pelvis, we found a prostate tumour. A transrectal ultrasound-guided needle biopsy confirmed the diagnosis. The patient underwent cystoprostatectomy and replacement ileocystoplasty and was followed by multi-agent chemotherapy. $\mathrm{PNET}$ / Ewing's sarcoma of the prostate is extremely rare. The prognosis is very poor, so we should pay enough attention to the differential diagnosis and treatment.

\section{Introduction}

Ewing's sarcoma and primitive neuroectodermal tumour (PNET) are primarily a tumour of soft tissues and bones; examples have been described at most sites. ${ }^{1}$ Ewing's sarcoma/PNET is reported to occur in various organs; however, it rarely occurs in the prostate. We report the seventh case of a primary Ewing's sarcoma/PNET of the prostate. We also review the relevant literature.

\section{Case report}

A 28-year-old male with no history of malignancy presented to our hospital with difficult defecation and anus distention. On digital rectal exam, a firm mass was felt on wall of the right rectum. There were no palpable lymph nodes. The magnetic resonance imaging (MRI) revealed a $7.4 \times 7.2 \times 6.1-\mathrm{cm}$ mass replacing the prostate gland, which appeared multi-lobulated and nodular masses had central septation. The tumour was in close contact with the posterior bladder with possible involvement of the bilateral seminal vesicle (Fig. 1). An abdominal ultrasound revealed a large mass near the prostate gland. There were multiple lung metastases in the bilateral lungs. There was no obvious lymphadenopathy or other metastases. The patient's serum prostate-specific antigen (PSA) level was $1.19 \mathrm{ng} / \mathrm{mL}$, and all the other serum tumour markers (such as carbohydrate antigen 19-9 [CA19-9], carcino-embryonic antigen [CEA], alpha-fetoprotein $[\mathrm{AFP}]$, lactate dehydrogenase [LDH] and prostate-specific acid phosphatase values) were within normal ranges. A prostate biopsy was performed and showed sheets of uniform small round blue cells, without glandular prostatic tissue. Immunohistochemical study confirmed the diagnosis of Ewing's sarcoma/PNET of the prostate.

The patient received cystoprostatectomy and replacement ileocystoplasty and was followed by multiagent chemotherapy. Histopathology of the operation specimens showed small and similar round cells (Fig. 2, part A). Immunohistochemical study revealed diffuse staining with anti-CD99 antibody and BCl-2 (Fig. 2, part B). The cells were negative for all other antibodies tested, including anti-keratin, $\mathrm{FCl}-1$, desmin, TTF-1, EMA, LCA (CD45), PCK, S-100 protein and synaptophysin. After treatment, the patient was recurrence-free at 12 months.

\section{Discussion}

Primary prostate sarcoma results from the mesenchymal components of the prostate stroma and accounts for less than $0.1 \%$ of primary prostate tumours. ${ }^{2}$ The Ewing's sarcoma/PNET is an extremely rare prostate sarcoma that mostly occurs in children and young adults, and is associated with a poor prognosis. Extraskeletal Ewing's sarcoma/ PNET mainly occurs in the paravertebral region, the chest wall and the lower extremities and less commonly in the pelvis, retroperitoneum or the upper extremities. Exceptional sites of occurrence include several organs of the genitourinary system, as well as many other visceral sites. ${ }^{1,3}$ Including our present case, there have been only 7 cases reports to date. ${ }^{3-8}$ The patients were young adults (median age 27 , range: 


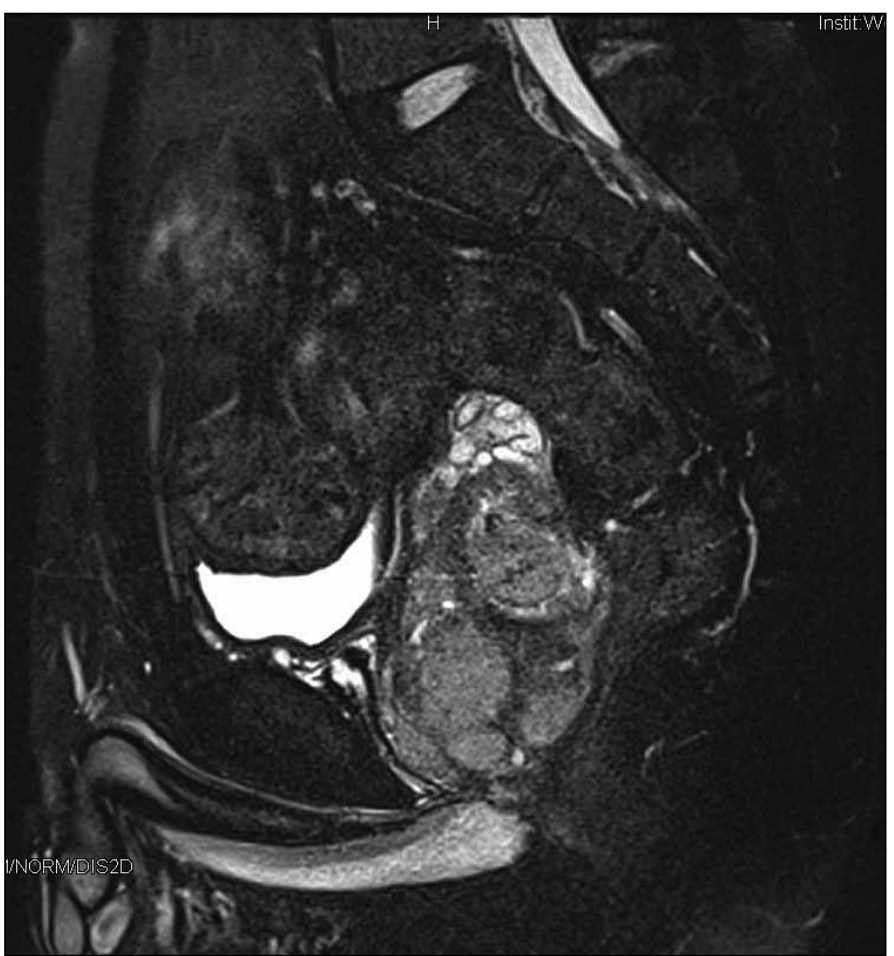

Fig. 1. A magnetic resonance imaging sagittal T2-weighted image: the prostate gland almost entirely was replaced by the tumour mass. The rectum was compressed posteriorly.

20-31). Four of these patients had complaints of miction pain, pelvic discomfort or dysuria. The PSA or the other serum tumour-associated markers of all cases were all normal. The MRI, computed tomography or transrectal ultrasound can locate these tumors. However, the MRI is more accurate. The diagnoses of these 7 cases were confirmed by the biopsy. Of the 7 cases, 5 received chemotherapy and the mass decreased in size. Four cases received radical surgery, including cystoprostatectomy and replacement ileocystoplasty or radical prostatectomy. External radiotherapy was performed in 3 cases. Based on these data, the radical surgery and chemotherapy may be needed to treat Ewing's sarcoma/PNET. However, data on the long-term follow-up have been limited; most patients were disease-free no more than 24 months after treatment.

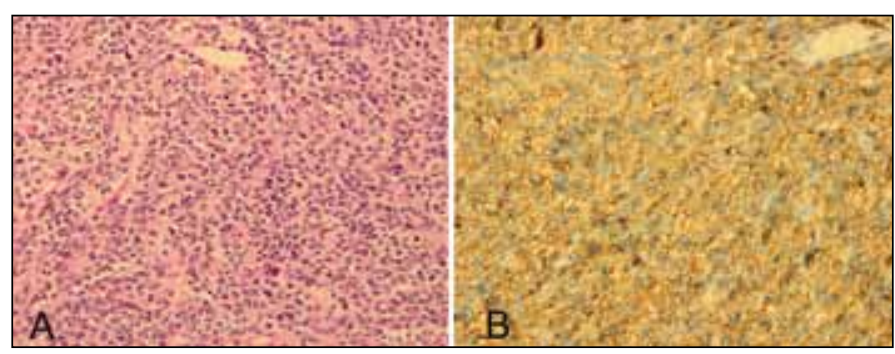

Fig. 2. A: Hematoxylin-eosin staining: small and similar round cells with round to oval nuclei (original magnification $\times 400$ ); B: Immunoperoxidase staining: membrane-associated CD99 reactivity (CD99 antibody, original magnification $\times 400)$.

\section{Conclusion}

Ewing's sarcoma/PNET of the prostate is extremely rare. The data from this neoplasm are also very scarce. As the prognosis is very poor, we should pay enough attention to the differential diagnosis and treatment.

Competing interests: None declared.

This paper has been peer-reviewed.

\section{References}

1. Dickman PS. Ewing's Sarcoma/Primitive Neuroectodermal Tumor. Pathol Case Rev 2000;5:60-70. http://dx.doi.org/10.1097/00132583-200005010-00007

2. Miedler JD, MacLennan GT. Leiomyosarcoma of the prostate. J Urol 2007;178:668. http://dx.doi.org/10.1016/i.juro.2007.05.036

3. Kumar V, Khurana N, Rathi AK, et al. Primitive neuroectodermal tumor of prostate. Indian J Pathol Microbiol 2008, 51:386-8. http://dx.doi.org/10.4103/0377-4929.42518

4. Mohsin R, Hashmi A, Mubarak M, et al. Primitive neuroectodermal tumor/Ewing's sarcoma in adult uro-oncology: A case series from a developing country. Urol Ann 2011;3:103-7. http://dx.doi.org/10.4103/0974-7796.82180

5. Funahashi $Y$, Yoshino $Y$, Hattori R. Ewing's sarcoma/primitive neuroectodermal tumor of the prostate. Int J Urol 2009;16:769. http://dx.doi.org/10.1111/i.1442-2042.2009.02339.x

6. Thete N, Rastogi D, Arya S, et al. Primitive neuroectodermal tumour of the prostate gland: ultrasound and MRI findings. Br J Radiol 2007, 80:e180-3. http://dx.doi.org/10.1259/bir/57293350

7. Peyromaure $M$, Vieillefond $A$, Boucher $E$, et al. Primitive neuroectodermal tumor of the prostate. J Urol 2003;170:182-3. http://dx.doi.org/10.1097/01.ju.0000065880.06201.5c

8. Colecchia M, Dagrada G, Poliani PL, et al. Primary primitive peripheral neuroectodermal tumor of the prostate. Immunophenotypic and molecular study of a case. Arch Pathol Lab Med 2003, 127:e190-3.

Correspondence: Dr. Xiang Li, Department of Urology, West China Hospital, Sichuan University, Chengdu, Sichuan 610041, China; fax: 86-02885422451; scimail@126.com 